\title{
Artigos
}

\section{Os pontos de vista do morador da periferia: 0 outro lado da política urbana ${ }^{1}$}

\author{
Maria Thereza Rosa Ribeiro*
}

\section{Resumo}

Este artigo tem por assunto as representações de grupos sociais, cujas práticas são (in)visíveis e (des)conexas em relação a políticas de planejamento da cidade. Discorre a representação dos moradores que vivem na periferia, não somente em virtude da desigualdade de distribuição de recursos econômicos, embora, por isso, atendidos por políticas sociais de Estado. Busca-se apresentar as entrevistas com lideranças de moradores de três loteamentos na cidade de Pelotas (RS) ${ }^{2}$, pelas quais se observa que a produção de significados do mundo vivido reproduz práticas culturais dominantes em espaços compartilhados por indivíduos possuidores de diferentes repertórios e visões de mundo. Constata-se, entretanto, que a "variação intraindividual" de significações oferece o repertório vinculado à "pluralidade de oferta cultural", como argumenta Lahire (2006. p. 54-55), e possibilita "resistir à legitimidade cultural dominante".

\section{Palavras-chave}

Representação. Periferia. Disposição intraindividual.

\section{Abstract}

This article is subject representations of social groups whose practices are (in) visible to policies regarding city planning. Discuss the representation of outskirts dweller that inhabit in

\footnotetext{
${ }^{1}$ Uma versão deste texto foi apresentada no XVI Congresso da Sociedade Brasileira de Sociologia 10 a 13 de setembro de 2013, Salvador, Bahia. Grupo de Trabalho 16: Movimentos Sociais na atualidade: reconfigurações das práticas e novos desafios teóricos.

* Doutora em Sociologia pela Universidade de São Paulo (USP); professora Associada do Departamento de Sociologia e Política e do Programa de Pós-Graduação em Sociologia, no Instituto de Filosofia, Sociologia e Política, da Universidade Federal de Pelotas. E-mail: mtherezaribeiro@gmail.com.

${ }^{2}$ Pelotas, município brasileiro localizado na região Sul do estado do Rio Grande do Sul.
} 
precarious urban spaces, not only because of the unequal distribution of economic resources, though, so, attended by social policies of the state. We seek to present interviews with leaders from residents of three urban settlements in the city of Pelotas (RS), in which we observed that the production of meanings of the lived world reproduces dominant cultural practices shared by individuals possessing different repertoires and worldviews spaces. We note, however, that the "intra-individual variation" of meaning is linked to the "plurality of cultural offer", as argued Lahire (2006, p.54-55) and enable "resist the dominant cultural legitimacy."

\section{Keywords}

Representation. Outskirts dwellers. Intra individual disposition.

\section{Introdução}

O contexto da pesquisa sobre as representações dos moradores da periferia foi desenhado no final da investigação do projeto Cidade, sociabilidade e desigualdade social ${ }^{3}$, que tratou a reformulação do planejamento municipal de Pelotas, especificamente do projeto do III $^{\circ}$ Plano Diretor, elaborado pelo Conselho do Plano Diretor (CONPLAD) de Pelotas no período de 2002 a 2006. O estudo convergiu para a análise da configuração do CONPLAD, pela qual se apreendeu a posição dos diferentes representantes da sociedade civil, do governo e do mercado (sobretudo promotores imobiliários), atinente à proposta de mudança do plano diretor do município de Pelotas. Também se levou em consideração o Estatuto das Cidades, lei federal n. 10.257, de 10 de julho de 2001, que regulamenta os artigos 182 e 183 da Constituição Federal e introduz diretrizes gerais da política urbana. Realizaram-se entrevistas tanto com representantes do $\mathrm{CONPLAD}^{4}$ quanto com lideranças de moradores

\footnotetext{
${ }^{3}$ Projeto de pesquisa aprovado com apoio financeiro do Conselho Nacional de Desenvolvimento Científico e Tecnológico - CNPq (2008-2010) e Fundação de Amparo à Pesquisa do Estado do Rio Grande do Sul - FAPERGS (2007-2011).

${ }^{4}$ Ribeiro, Maria Thereza Rosa. "Políticas de participação: o lugar do ator/agente na reconstituição da cidadania”. In: Léo Peixoto Rodrigues; Marcus Vinicius Spolle (Orgs.); Sociologia: conexões pertinentes. Pelotas: Editora UFPel, 2012, v. 1. p. 169-196. Ribeiro, Maria Thereza Rosa. "Cidade e desigualdade: os novos arranjos institucionais e repercussão sociopolítica”. In: Rosângela Marione Schulz (Org.); Ensaios de Sociologia e Política. Pelotas: Editora UFPel, 2010, v. 1. p. 177201. Ribeiro, Maria Thereza Rosa; Pereira, Alaídes Catarina dos Santos. Práticas Participativas e Conselho de Gestão das Cidades. Pensamento Plural - UFPel, v. 6, p. 71-95, 2010.
} 
que coabitam na região centro/periferia da cidade de Pelotas.

$\mathrm{Na}$ época da pesquisa, averiguava-se, em entrevista com as lideranças de moradores, se a discussão do plano diretor contribuiu de fato para a construção de um espaço de negociação e intervenção no território. Portanto, indagava-se se ao morador de baixa renda estava aberta a possibilidade de participar do debate do novo plano diretor, realizado em fóruns, conferências da cidade, e da escolha de porta-voz (mediador) no CONPLAD, a fim de encaminhar demandas por melhorias de saneamento básico, de infraestrutura, moradia etc. O objetivo das entrevistas foi o de conhecer os pontos de vista das lideranças de moradores e a situação em que vivem, bem como perceber a potencialidade da ação das lideranças para estabelecer redes de negociação e de vínculos sociais na esfera pública. A hipótese da pesquisa era de que o debate do plano diretor robusteceria o potencial da ação não só dos atores instituídos pela condição de cidadania, a exemplo dos representantes do CONPLAD, porém também dos moradores da periferia, classificados pela cultura dominante como cidadãos de segunda categoria em virtude da condição de pobreza.

Por fim, chegou-se ao resultado de que para os representantes de entidades (ONGs, sindicatos, associações etc.) participantes do CONPLAD, é difícil legitimar demandas que emanam de propostas dos grupos sociais os quais as entidades representam, em virtude da correlação de forças com os promotores imobiliários (sobretudo a construção civil). Essa situação leva muitas vezes à desistência dos representantes da sociedade civil de participar de conselhos e fóruns de discussão de assuntos públicos. Já para os moradores da periferia, se a possibilidade de atuar e decidir, nos espaços institucionalizados, é mais remota, resta-lhes a ação coletiva nos enfrentamentos públicos, a qual desvela a necessidade de melhores condições de moradia e infraestrutura urbana, e a denúncia da desigual oportunidade de acesso a bens, equipamentos e serviços nos centros urbanos.

\section{Delimitação do espaço dos moradores da periferia}

O objetivo deste artigo é tratar dos pontos de vista dos moradores da periferia, no que tange à condição de moradia e percepção dos laços sociais advindos do lugar onde estão situados. Discorrer sobre a representação dos moradores que vivem na periferia, não somente em virtude da desigualdade de distribuição de recursos econômicos, embora, por isso, atendidos por 
políticas públicas estatais. Para definir a periferia, atenta-se a referência a duas variáveis: renda familiar e propriedade, tendo em vista localizar grupos sociais não proprietários que coabitassem nas regiões centro / periferia de Pelotas. Conforme o censo do IBGE (2000): “o não proprietário é o que não tem imóvel próprio, sejam os que pagam aluguel, posseiros ou moram de favor/cedido em um domicílio, com renda entre 1 a 3 salários mínimos familiar com referência ao salário mínimo nacional (SM/BR)" (IPO, 2002, p. 9$)^{5}$.

Cabe mencionar que, em 2000, o diagnóstico do déficit habitacional em Pelotas era estimado em 14 mil domicílios - entre urbanos e rurais - para uma população urbana de 297.825 e rural de 25.333 habitantes. Atualmente, a zona urbana de Pelotas atinge uma população de 306.193 habitantes e a rural, 22.082 (IBGE, 2010). A cidade possui 113 mil domicílios cadastrados no IPTU, e seu déficit habitacional é de 11,93\% (aproximadamente 13.598 domicílios). Esse índice é considerado elevado se comparado a cidades brasileiras de médio porte, as quais apresentam em média $6 \%$ de carência habitacional ${ }^{6}$.

A informação geral do déficit habitacional de Pelotas ainda contribui para selecionar os moradores de renda familiar de 0 a 3 salários mínimos (S.M) que vivem em domicílios precários nas regiões: Fragata (Zona Oeste), Areal / Laranjal (Zona Leste) e Centro/Porto (Zona Central/ Zona Sul). Com base nesses dados, busca-se conhecer os problemas urbanos e sociais, especificamente nos loteamentos: Navegantes I e II, ambos localizados entre Areal e Centro; Anglo nas regiões Centro/Porto e FRAGET (Associação das Vilas Reunidas Farroupilha, Real, Aurora, Guabiroba, Elza, Treptow) na Fragata. A situação socioespacial dessas áreas consiste em loteamentos com moradia e infraestrutura precárias, com assentamentos em áreas de risco e com falta de regularização fundiária. Os loteamentos Navegantes I

\footnotetext{
${ }^{5}$ Os dados da pesquisa do Instituto de Pesquisas de Opinião (IPO) sobre o déficit habitacional da zona urbana de Pelotas, levantados no mês de maio de 2002, serviram de referência para a escolha das localidades onde moram moradores de baixa renda, de zero a três salários mínimos.

${ }^{6}$ Informações do Plano Local de Habitação de Interesse Social (PLHIS), apresentado na audiência pública que integrou a $5^{\text {a }}$ Conferência Municipal da Cidade, promovida pela Secretaria de Gestão da Cidade e Mobilidade Urbana (SGMU) de Pelotas em 15 de junho de 2013. Fonte: http://www.pelotas.rs.gov.br/noticias/detalhe.php?controle=MjAxMy0wNi0xNQ= $=\&$ codnoticia $=34439$. Acesso em: 09 de agosto de 2013.
} 
e II, Fraget e Anglo estão localizados em áreas próximas à região central da cidade de Pelotas, embora configurem a periferia, cujos moradores de origem das classes trabalhadoras percebem, no dia a dia, a ínfima aplicação de investimentos públicos voltados para melhorar as condições de habitação, serviços de água e esgoto, equipamentos urbanos, bem como oferta de emprego.

Tem-se o entendimento de que os limites de acesso aos serviços urbanos e seu substrato à terra caracterizam o espaço da periferia como campo de reprodução de desigualdades sociais. Sob o aspecto econômico, a existência da periferia pode significar e abranger "as parcelas do território da cidade que têm baixa renda diferencial", como a definem os autores Bonduki e Bonduki (1979, p. 147). Isto é, na concepção marxiana, a renda diferencial e a renda absoluta são componentes distintos da renda fundiária. Ao transpor essa distinção ao processo de urbanização, Bonduki e Bonduki esclarecem que a renda diferencial se constitui "nas diferenças entre as condições físicas e localizações dos terrenos e nos diferenciais de investimentos sobre eles, ou no seu entorno, aplicados." Esse componente de renda diferencial se adiciona à renda absoluta que deriva da remuneração paga na forma de aluguel e compra de terreno, em virtude da existência da propriedade privada (BONDUKI; BONDUKI, 1979, p. 147). O acesso a serviços urbanos, a exemplo de transporte, serviços de água e esgoto, energia elétrica, escola, comércio etc., propicia a valorização de localidades urbanas, cuja demanda para fins de moradia também expressa a busca de incorporar o status da vizinhança. Contudo, a população pobre, desempregada e de baixa renda fica relegada às áreas com menor aplicação de serviços urbanos, por essa razão, paga um preço muito baixo pelo direito de morar.

Entretanto, como enfatiza Singer (1979, p. 27-28), há de se considerar a dessemelhança entre o caráter diferencial da renda da terra urbana paga pelas empresas imobiliárias e pelos consumidores. As empresas têm em vista o máximo proveito retirado, principalmente, da situação privilegiada de áreas bem servidas para ocupação dos grupos sociais de renda mais elevada. Isso confere a renda de monopólio da promoção imobiliária, a qual instiga a privilegiar determinadas localidades "em medida tanto maior, quanto mais escassos forem os serviços em relação à demanda” (SINGER, 1979, p.27). Já a renda diferencial paga pelos consumidores (moradores) "depende de sua quantidade, da repartição da renda pessoal e de necessidades míticas que a própria promoção imobiliária cria.” (SINGER, 1979, p.28).

Nesses termos, a periferia é caracterizada, empiricamente, como a 
localidade com baixo investimento em serviços urbanos, ou pior servida por estes, por isso o preço de morar é mais barato, e o prestígio social de quem nela habita é depreciado no mercado econômico e simbólico dominante. Essa classificação de periferia vincula "a ocupação do território urbano à estratificação social", portanto também a formação de espaços de segregação social, como afirmam Bonduki e Bonduki (1979, p. 148), bem como Singer (1979, p.27). Em analogia ao "subúrbio" analisado por Martins (1992), ainda em termos quantitativos, a produção do espaço "periferia" implica a predominância de "a renda fundiária e a riqueza imobiliária e a pobreza que delas decorre" (p. 16) sob a especulação dos preços dos imóveis. A periferia está distribuída no espaço urbano não apenas como espaço de exclusão, mas também de reprodução das relações sociais implícitas na expansão das cidades.

Essas definições econômicas de periferia convertidas à perspectiva sociológica de Bourdieu (1989; 1996) significam relacionar as condições geográficas ou físicas de localização dos terrenos, que podem aproximar os agentes numa região mais homogênea do espaço urbano, com a distribuição das diferentes espécies de capital (econômico, cultural, simbólico) que as distanciam no espaço social. Apesar da proximidade geográfica e física inter e intra às regiões centro e periferia, as distâncias sociais pressupõem o distanciamento no espaço de relações hierarquizadas pela distinção de modos de vida e de preferências, sustentadas pela posição de agentes em diferentes campos de concorrências, disputas e reciprocidades. Nesse sentido, a aproximação predispõe pessoas situadas em posições superiores, inferiores ou intermediárias, em determinada microrregião, dadas a características mais homogêneas do tipo de capital cultural herdado, adquirido e institucionalizado, incorporado ao mesmo tempo ou sucessivamente. A incorporação de similares tipos e padrões de propriedades (habilidades), bens, preferências, gostos etc. fazem as pessoas estarem mais perto umas das outras, portanto "mais inclinadas a se aproximar; e também mais fáceis de abordar, de mobilizar" (BOURDIEU, 1996, p. 25) o poder simbólico que o agente suporta.

Sendo assim, as diferenças das espécies de capitais (econômico, cultural) adquiridas e incorporadas pelos agentes e grupos sociais, durante momentos diferentes de suas vidas, estruturam o campo hierarquizado pela diferenciação do lugar no espaço constituído relacionalmente. Apreende-se da leitura bourdieusiana, portanto, que na prática o que existe são estratos de grupos relativamente homogêneos que ocupam o espaço social de forma diferencial 
em razão dos diversos capitais que possuem. Por sua vez, a periferia pode ser concebida como campo diferencial de significados os quais são produzidos, conforme condições sociais e situações históricas, pelas variações cognitivas dos agentes a respeito do mundo em que vivem.

Por fim, considera-se que "a baixa renda diferencial" e as variações das disposições de significados dos agentes no campo de disputas, concorrências e reciprocidades configuram a periferia como espaço de diferenciação hierárquica de status negativo, que reproduz o espaço urbano mais amplo. Contudo não é um espaço exclusivamente homogêneo, pois se pode considerar que há múltiplas periferias, como explicitam Bonduki e Bonduki (1979, p.148):

(...) não existe uma única periferia uniforme, mas muitas, com características diferentes, pois mesmo dentre os territórios da cidade mal servidos, há uma graduação e uma hierarquização muito grande, desde o que não tem ruas até o que tem água e não asfalto, etc., nas mais diversas localizações.

Desse modo, ainda retomamos Bonduki e Bonduki (1979, p.148) para afirmar que entre as "várias periferias",

a população de baixa renda se deslocará, vendendo sua casa e mudando seu local de moradia; provavelmente, se deslocará no sentido do gradiente declinante da renda diferencial, ou seja, de uma periferia para outra mais carente, reproduzindo seu espaço para reproduzir sua força de trabalho.

Por outro lado, em termos qualitativos, a periferia é o lugar do habitat, lugar para "comer, dormir e trabalhar, reproduzir-se" conforme Lefebvre (2008, p. 78), porém também "lugar do vivido" enquanto memória fragmentária da experiência cotidiana concebida como senso comum. Este exerce a função ideológica e de representação "que cimenta a unidade contraditória dessas aparentes dicotomias" do lugar para morar e trabalhar (MARTINS, 1992, p. 15). No movimento de busca de memória, o sentido da historicidade privada e esmagada de sentidos pelo poder dominante da "História" da reprodução das relações é descoberto cotidiano e fragmentário, como mundo significativo do "vivido" reprimido e esquecido, como salienta Martins.

O cotidiano é o espaço vulnerável e resistente cuja estrutura corpórea possibilita refutar "a reprodução das relações que o esmagam e o privam de tudo.” (LEFEBVRE 1977, p. 251). Similar ao corpo, o cotidiano é o 
"Fundamento tanto das necessidades e do desejo, como das representações e dos conceitos, sujeito e objeto filosóficos e, mais e melhor, base de toda a práxis e de toda a reprodução", portanto é o foco de resistência, se não ostensiva, silenciosa, “à reprodução das relações opressivas”, Lefebvre conclui.

Por fim o contraste dos argumentos dos autores supracitados colabora para avançar o enfoque bourdieusiano de estudo de microrregiões homogêneas onde os agentes sociais estruturam o campo hierarquizado pelas disposições relacionalmente incorporadas, adquiridas e institucionalizadas. Tem-se em vista compreender o vivido, o lugar onde está retido o sentido da ação precedida e esmagada pela unicidade da "oferta cultural dominante" (LAHIRE, 2006), a partir da reação dele (do vivido) ao poder simbólico (força opressiva) do espaço constituído pelo qual atravessa a manifestação de vários pontos de vista "repertórios, hábitos e disposição de agir e crer" (LAHIRE, 2002; 2006).

A observação direta da ação dos moradores da região centro-periférica da cidade de Pelotas propicia apreender esses repertórios que traduzem a percepção dos moradores referida à situação da localidade e do lugar onde coabitam. O propósito é o de ressaltar, por meio das disposições de agir e crer dos agentes, o potencial de resistência dos grupos sociais que pode ser constatado, como diz Lahire (2006, p.54), na

variação intra-individual das práticas e das preferências culturais [que] constitui o traço e o sintoma, na escala do social incorporado, da pluralidade da oferta cultural, de um lado, e da pluralidade de grupos sociais, de outro (dos mais micro aos mais macro), capazes de sustentar (suportar) essas diferentes ofertas culturais específicas, que compõem nossas formações sociais altamente diferenciadas.

Entende-se que a trajetória do indivíduo se realiza numa pluralidade de contextos sociais, seja a família, os amigos, o trabalho, a associação, o clube, a escola etc., onde as experiências socializadoras fornecem, durante momento simultâneo ou sucessivo em quaisquer desses contextos, os "quadros sociais da memória” dos indivíduos (HALBWACHS apud LAHIRE, 2002, p. 31). A partir das práticas desempenhadas em múltiplos contextos, é possível descobrir a heterogeneidade de pontos de vista e a variedade de tipos de experiências sociais. Ou seja, os indivíduos internalizam a pluralidade de práticas, de preferências culturais, de inclinações, de disposições etc. como quadro social de memória (o vivido), cujo produto são os repertórios dos 
hábitos que traduzem as variações intraindividuais escoradas em diferenciados contextos dos quais os indivíduos participam.

\section{A periferia: espaço diferencial de reprodução de relações sociais}

Em janeiro e fevereiro de 2009, a investigação empírica foi desenvolvida com estudos exploratórios nas localidades Navegantes (situada entre as regiões Centro e Areal), Anglo (Centro / Porto) e por último no FRAGET (Reunião de Vilas Farroupilha, Real, Aurora, Guabiroba, Elza, Treptow) na região Fragata, e com sete entrevistas realizadas com os moradores desses loteamentos. Contudo, neste artigo, acrescentam-se informações sobre intervenções de programas sociais e institucionais implantados a partir de 2010 que alteraram as relações sociais nos loteamentos referidos, assim como pontos de vista sobre a discussão do III ${ }^{\circ}$ Plano Diretor do município de Pelotas.

\section{Características físicas e sociais específicas da periferia (dos loteamentos)}

O Loteamento Navegantes é dividido em Navegantes I, II e III. Nos dois primeiros, observou-se que possuem uma estrutura melhor em relação ao Navegantes III. Nesse último, as ruas não possuem calçamento, e as ligações de água e luz são realizadas pelos próprios moradores, ao passo que o Navegantes I e II apresentam calçamento e algumas ruas asfaltadas, a água e a luz fornecidas pelos $\mathrm{SANEP}^{7}$ e $\mathrm{CEEE}^{8}$, esgoto canalizado (na maioria das ruas). Um posto de saúde atende as três divisões do Loteamento Navegantes.

A associação de moradores do Navegantes I possui estatuto e está registrada em cartório, mas ainda não tem sede. Todos os anos, os moradores se reúnem para a realização de festas e eventos comemorativos. Por sua vez, no Navegantes II, a Associação dos Moradores do Bairro Navegantes (AMOBAN) possui

\footnotetext{
${ }^{7}$ Empresa de Serviço Autônomo de Saneamento de Pelotas, Rio Grande do Sul.

${ }^{8}$ Companhia Estadual de Energia Elétrica, do Rio Grande do Sul.
} 
sede própria, onde realizam cursos de alfabetização de adultos, de artesanato para donas de casa: tricô, renda, costura etc. O loteamento Navegante III é o que possui a pior condição física e de localização, por isso não foi possível entrevistar os moradores.

No Loteamento Anglo, localizado na região Porto, das 150 famílias moradoras, aproximadamente 90 estão assentadas em área de risco. A comunidade não dispõe de saneamento básico, a rede de energia elétrica e de abastecimento de água é clandestina, as ruas estreitas, não há calçamento nem esgoto canalizado ou coberto. A maioria das casas de madeira é construída com material precário. Todo o lixo é jogado no Arroio Pepino, que passa ao lado do loteamento. O mesmo arroio deságua no Canal São Gonçalo. É comum ocorrer enchente nessa área, pois o terreno é baixo à beira do arroio, portanto sempre inunda com o excesso de chuva. A fonte de renda das famílias é o Programa Bolsa Família ${ }^{9}$, e a complementam como o trabalho de catadores de lixo. A comunidade possui uma associação de moradores, porém carece de uma sede, e as reuniões são realizadas na rua.

A partir de 2010, as condições habitacionais e de infraestrutura do Loteamento Anglo têm se alterado, devido ao fato de o município de Pelotas em 2008 ter sido contemplado com o Programa de Aceleração do Crescimento (PAC) - Farroupilha, pelo qual obteve recurso para diversas obras, entre elas quatro conjuntos habitacionais: Anglo, Ceval, Vila Farroupilha e Osório. ${ }^{10}$

\footnotetext{
${ }^{9}$ O Programa Bolsa Família (PBF) criado pelo Governo Lula em 2003 é um programa de transferência direta de renda com condicionalidades que beneficia famílias em situação de pobreza e de extrema pobreza em todo o País. O Bolsa Família integra o Plano Brasil Sem Miséria (BSM, do Ministério do Desenvolvimento Social e Combate à Fome), que tem como foco de atuação os 16 milhões de brasileiros com renda familiar per capita inferior a $\mathrm{R} \$ 70,00$ mensais, e está baseado na garantia de renda, inclusão produtiva e no acesso aos serviços públicos. A seleção das famílias para o PBF é feita com base nas informações registradas pelo município no Cadastro Único para Programas Sociais do Governo Federal, instrumento de coleta de dados que tem como objetivo identificar todas as famílias de baixa renda existentes no Brasil. Fonte: www.mds.gov.br. Acesso em: 11 de dezembro de 2011.

${ }^{10}$ A assinatura do contrato foi realizada, em maio de 2008, pelo então prefeito Fetter Júnior (PP), e a contratação da empresa Artefatos de Concreto Pedro Osório (ACPO), vencedora da licitação para as obras de infraestrutura - rede de esgotos, terraplanagem, pavimentação e rede de água -, ocorreu em dezembro. No final de abril de 2009, a empresa foi liberada para começar as obras. Um ano após, o empreendimento vencedor do projeto de licitação para construção das casas - não só do Anglo, como do Ceval e do Osório -, Pérgola Arquitetura Construção e Restauração Ltda, abandonou o canteiro de obras devido a problemas financeiros. Seis meses mais tarde a prefeitura rescindiu o contrato e teve de abrir um novo processo de licitação com os valores atualizados. A contratação de outra empresa, Quality Engenharia Ltda, vencedora da nova licitação, porém, só ocorreu um ano depois, em setembro de 2011. Fonte: http:// cufapelotas-rs.blogspot.com.br/2013/07/atraso-na-entrega-do-loteamento-anglo.html. Acesso em: 09 de agosto de 2013.
} 
No que tange aos recursos destinados ao Anglo, o valor total da obra, firmado desde 2008, é de $\mathrm{R} \$ 3$ milhões, a serem gastos $\mathrm{R} \$ 1,6$ milhão com as habitações, $\mathrm{R} \$ 1,2$ milhão com infraestrutura e $\mathrm{R} \$ 200$ mil com o Centro comunitário. Este último foi entregue, recentemente, na segunda semana de julho de 2013. O recurso para habitação abrange gastos com a construção de 90 casas. Entre janeiro e março de 2012, 58 famílias sorteadas receberam suas respectivas casas. As 32 famílias restantes, entre elas oito tiveram sua antiga casa retirada devido à necessidade de espaço para execução das obras no loteamento, essas famílias aguardam a construção das moradias. As novas casas têm dois pequenos quartos, sala conjugada à cozinha e um banheiro. As famílias do Anglo esperam a continuação das obras da rede elevatória de esgoto que está parada, bem como os ajustes na infraestrutura da rede de esgotos, terraplanagem, pavimentação e rede de água. ${ }^{11}$

Por último, nas vilas FRAGET atua a Associação de Catadores de Lixo, onde 12 famílias garantem seu sustento, trabalhando diretamente com reciclagem de lixo. Também aproximadamente 60 famílias se beneficiam da coleta de lixo e vendem para a mesma associação. Na época da entrevista, os associados reclamavam da falta de reconhecimento da Associação de Catadores de Lixo pelos poderes públicos locais. Eles enfrentam dificuldades quanto à ausência de infraestrutura adequada para o funcionamento do local de reciclagem de lixo. A associação oferece curso para alfabetização de adultos. A comunidade do FRAGET conta com o atendimento de um posto de saúde para as vilas Farroupilha, Real, Aurora, Guabiroba, Elza e Treptow. Os moradores queixavam-se de problemas, sobretudo da Vila Farroupilha, como a falta de saneamento básico, de transportes coletivos, de iluminação e o crescimento da violência.

\section{Repertórios do morador da periferia}

Com as entrevistas, buscou-se conhecer os repertórios das lideranças de moradores, as variações intraindividuais concernentes às disposições e

\footnotetext{
${ }^{11}$ Dos loteamentos do Programa de Aceleração do Crescimento (PAC) Farroupilha, apenas o Ceval foi entregue. O Osório, assim como o Barão de Mauá - construído para as 152 famílias vítimas das enchentes de 2009 que moram em área de risco -, aguarda o término de uma rede elevatória de esgoto que está em construção e ajustes na infraestrutura. Algumas casas do Barão de Mauá foram, porém, entregues pela Prefeitura de Pelotas em junho de 2012. Fonte: http:// cufapelotas-rs.blogspot.com.br/2013/07/atraso-na-entrega-do-loteamento-anglo.html. Acesso em: 09 de agosto de 2013.
} 
hábitos (LAHIRE, 2002, 2006), manifestos em narrativas heterogêneas sustentadas no trabalho, na família, na escolaridade e nas preferências culturais. Também se tratou sobre o significado do plano diretor da cidade, se os moradores haviam participado dos fóruns de discussão e encaminhado demandas. Se o espaço democrático de reformulação do plano de diretor (2002-2008) foi aberto aos moradores da periferia, sobretudo os de baixa renda, a possibilidade de reivindicar melhorias à situação precária - falta de saneamento básico, de infraestrutura, de moradia, serviços etc. em que vivem. Quais são as estratégias para tornar visíveis os problemas e as demandas dos moradores da periferia?

As respostas obtidas com quatro lideranças dos loteamentos: a primeira, do Navegantes I; a segunda, do Navegantes II; a terceira, do Anglo, e a última com os membros da Associação de Catadores do FRAGET, seguem:

1. A liderança dos moradores do Loteamento Navegantes I tem 31 anos. Possui ensino fundamental incompleto (até $5^{\underline{a}}$ série). Ele é operário, trabalha na Secretaria de Cidadania do Município de Pelotas. Já foi filiado ao Partido PDT. Gosta de futebol e maratona. Vive uma união estável há 11 anos, possui dois filhos (um, é da primeira união da sua mulher; outro é de ambos). A mulher é agente comunitário, trabalha no Posto de Saúde do Navegante II, possui ensino fundamental completo. Ele assiste ao jornal da TV Record, ao programa de TV Fantástico aos domingos. Admira o jogador Ronaldinho, a música sertaneja do cantor Zeca Camargo e o ator Tarcísio Meira. Não participou dos fóruns de discussões do plano diretor, porque não foi chamado para participar e argumentou: "Talvez por não ter um ponto de referência [uma sede da associação], eles [Prefeitura e a Câmara de Vereadores] não chamam". Disse que os moradores encaminham reivindicações à Prefeitura: "Todos os anos, qualquer dia. Tenho mais relação com os secretários, porque sou funcionário da Prefeitura e, hoje, também filiado ao Partido (PPS). Assim, eles atendem os pedidos (sic) diretamente, na maioria das vezes."

Outros moradores do Navegantes I apresentaram pontos de vista similares ao da liderança da associação, não sabem o que é o plano diretor da cidade e acham que a associação de moradores deve ter mais apoio da prefeitura. Uma das moradoras mencionou: "Através da ONG CAPA [Centro de Apoio do Pequeno Agricultor] e das reuniões das mulheres organizadas pela vereadora do Partido PT [Miriam Marroni] no salão da sede da Igreja Nossa Senhora de Fátima, nós [os moradores] tomamos conhecimento do plano 
diretor. No entanto, nunca fomos chamados a participar de nada, eles vinham aqui para apresentar as propostas. Eles [ONG CAPA e PT] propunham melhorias para o bairro e tal, envolvendo o partido político".

Nessa entrevista com a liderança e com os moradores do Navegantes I, por um lado, depreende-se o repertório que acede à "oferta cultural dominante" de gostos e preferências culturais reservados às classes populares. Por outro, os moradores fazem parte, embora apartados dos espaços de decisão institucionalizados, como o CONPLAD, do sistema de troca mediado pela reciprocidade de dar, receber e retribuir (MAUSS, 2003), onde os doadores - moradores, partidos políticos, prefeitura e ONGs - aparecem como atores independentes e individuais, cada um dos quais se constitui num reprodutor do sistema de troca simbólica marcado pela necessidade. Ou seja, a troca é requerida pela necessidade de reciprocidade, e essa reciprocidade é exigida pela necessidade de troca, como um "sistema de prestações totais" ou contratuais, como menciona Mauss (2003, p. 191).

2. A liderança do Navegantes II tem 51 anos. Está terminando o ensino médio, turno noturno, no Colégio Assis Brasil. Já foi operária na fábrica de enlatados Pomberang, hoje é cabeleireira. Ela é casada há 35 anos, o marido é comerciante aposentado. Tem quatro filhos. Gosta de caminhar, de festa e de carnaval. Frequenta a praia Barro Duro (Balneário da Laguna dos Patos). Assiste na televisão ao jornal e à novela. Gosta de literatura espírita. A respeito da associação de moradores, ela mencionou: "O pessoal [moradores] busca a associação quando precisa recorrer ao poder público”. Quanto à assembleia: "os moradores nos procuram e marcamos uma reunião para debatermos os problemas, e elaboramos um abaixo assinado." Em relação ao plano diretor, ela disse: "Não estou bem informada, não sei o que é plano diretor."

Ela também comentou sobre "a importância da atuação da ONG C.A.P.A. (Centro de Apoio ao Pequeno Agricultor) com a distribuição de cesta básica do Programa Fome Zero"12. Além

\footnotetext{
${ }^{12} \mathrm{O}$ Programa Fome Zero é um programa do governo federal de combate à fome (Governo Lula, 2003), o qual engloba o Programa Bolsa família mediante a unificação dos programas implantados no Governo FHC (1995-2002), idealizados pela então primeira-dama D. Ruth Cardoso: "Bolsa Escola", "Auxílio Gás" e "Cartão Alimentação". Fonte: www.mds.gov.br. Acesso em: 11 de dezembro de 2011.
} 
disso, "eles fornecem cursos de capacitação aos moradores.". A representante da comunidade Navegantes II ressaltou a necessidade de políticas de geração de emprego para inclusão dos moradores no mercado de trabalho local.

Essa moradora, presidente da associação do loteamento Navegantes II, atua de maneira mais engajada na causa de solução de problemas sociais dos moradores do loteamento. Ela estabelece razoável comunicação com os demais moradores e organiza demandas de emprego, de curso de capacitação, de distribuição de alimento com a ONG C.A.P.A., e recepciona as denúncias dos problemas de moradia e de precária oferta de serviços urbanos. Resolver essas questões requer mobilizar os residentes do loteamento para que participem de reuniões da associação do Navegantes II e encaminhem petições, abaixo assinado etc. ao poder público municipal. Também a presidente da associação de moradores busca articular essa ação coletiva à ONG C.A.P.A., cuja atuação no loteamento é tanto de mediação com o poder público como de copartícipe das demandas dos moradores.

3. No Loteamento Anglo, o líder da associação de moradores tem 39 anos. Possui ensino fundamental incompleto (até a $7^{\mathrm{a}}$ série), fez curso de mecânico na FEBEM (por decisão de seu avô). Vive uma união estável há oito anos. A mulher é dona de casa. Eles têm um afilhado, filho do seu irmão. Gosta de futebol, novela e de pescar na região da Balsa [próxima ao Anglo, na orla do Canal São Gonçalo]. Não tem filiação partidária. Sobre a frequência dos moradores nas reuniões da associação, respondeu:

"Vamos de casa em casa chamar o pessoal, as reuniões são na esquina, pois não temos sede, comparece quase todo mundo, só faltam por motivo de trabalho. Depois a gente vai pra cima do prefeito e também pra Secretaria de Habitação. Quando a gente quer alguma reunião, falo com o vereador do Partido PR [Waldomiro Lima] que serve de intermediário para se chegar ao prefeito. O vereador conseguiu colocar o Anglo no programa do PAC [Programa de Aceleração do Crescimento]."

Ao ser questionado sobre o plano diretor, ele respondeu: "Não, nunca fui chamado para os fóruns de discussão."

Também entrevistamos uma família de moradores composta pelo casal e cinco filhos pequenos na faixa etária de 2 a 10 anos. A 
assistente social do Programa Primeira Infância Melhor (PIM) ${ }^{13}$, apresentou-nos a dona de casa e visitamos a casa dessa família, que ficava na frente de um terreno estreito ao longo do Arroio Pepino no Anglo. A dona de casa concordou em participar da entrevista. Ela de imediato tratou sobre remoção de sua casa que estava prevista pelo Projeto PAC - Farroupilha, e demonstrou preocupação, dizendo: "Eu e meu marido sabemos que moramos em área de risco, mas nossa casa é ajeitada e o terreno é grande. A nossa casa é de madeira e tem cinco peças e um banheiro. As crianças brincam no pátio (...)”. Perguntamos se ela já conhecia a planta da nova casa: "Sim. Os funcionários da prefeitura disseram que receberemos uma casa com dois pequenos quartos, sala junto com a cozinha e um banheiro. "Eu e meu marido não estamos satisfeitos, porque o tamanho da nova casa é muito pequeno para nos acomodar com os cinco filhos.” Em 2012, esta família foi contemplada com a nova moradia no Loteamento Anglo, do Projeto PAC - Farroupilha.

O loteamento Anglo em relação aos outros dois tratados anteriormente é o que possui as piores condições físicas e ambientais, e os moradores pleiteavam, para viabilizar o plano de urbanização do loteamento, recursos do PAC. Eles organizaram essa demanda para constituir um sistema de troca - dar, receber e retribuir (MAUSS, 2003) - com outros atores, o político mais próximo à causa dos moradores, a assistente social, a imprensa, a ONG C.U.F.A. (Central Única das Favelas), esses vínculos locais robusteceram a ação de enfrentamento dos moradores com o poder público, prefeito e secretaria de habitação. Por outro lado, a parceria da promoção imobiliária com a Prefeitura de Pelotas, relação mediada pela política pública do PAC (Programa de Aceleramento do Crescimento), oferece um modelo de planejamento urbanístico absolutamente uniforme e unívoco, desconexo das reais necessidades (tamanho das habitações) de cada família de

\footnotetext{
${ }^{13}$ Programa social sob a coordenação da Secretaria da Saúde do Governo Estadual do Rio Grande do Sul, e apoio das secretarias de Educação, Cultura, Trabalho e Desenvolvimento Social, com sede em Pelotas no Posto de Saúde do Navegante I. Esse programa institucional de ação socioeducativa, desenvolvido pelo governo estadual desde 2003, tornou-se lei estadual em 2006. Seu objetivo é o atendimento às famílias com crianças de zero a 6 anos e gestantes, que se encontram em situação de vulnerabilidade social. As famílias também estão cadastradas no Programa Bolsa Família. Fonte: http://www.pim.saude.rs.gov.br/a_PIM/php/paginaQuemSomos.php. Acesso em: 09 de agosto de 2013.
} 
trabalhadores. Na incerteza da possibilidade de acesso aos recursos para viabilizar obras no espaço diferencial, afirma a liderança da associação do Loteamento Anglo: “a solução é ocupar a Câmara de Vereadores”, episódio acontecido na audiência pública de 14 de junho de 2013. Ainda ele conclui: "pressionar o prefeito para terminar as obras do PAC-Farroupilha nesse loteamento".

4. Na localidade da Associação das Vilas Reunidas do FRAGET, foram entrevistadas três moradoras, e uma assistente social que atua na localidade $^{14}$. As moradoras disseram que enfrentam problemas na Associação de Catadores do FRAGET, devido à exigência da prefeitura (gestão do partido $\mathrm{PP}$ ), que trata da regularização do espaço físico, do galpão onde manejam a seleção do lixo. A prefeitura, segundo elas, estipulou um prazo para a regularização de instalações apropriadas ao trabalho de reciclagem, porém a associação enfrenta problemas financeiros para executar as obras no mesmo estabelecimento. Também informaram: "a comunidade já teve um representante no CONPLAD [Conselho Municipal do Plano Diretor de Pelotas] que reivindicou verbas para a melhoria da comunidade, também recursos do PAC para Vila Farroupilha”. A assistente social contou que participou no grupo temático de Habitação Social - Estudo das Áreas de Interesse Especial Social -, formado por arquitetos, geógrafos e assistentes sociais, da UFPel, da UCPel e da Prefeitura Municipal de Pelotas. Ela informou que o mesmo grupo temático participou do CONPLAD no período de 2002 a 2006: "tratou de analisar a localização das áreas de habitação social e em demarcar os vazios urbanos, a fim de contribuir para uma política pública com vistas ao controle e fiscalização uso e ocupação do espaço”.

Diferentemente dos outros três loteamentos, a FRAGET escolheu um representante para o CONPLAD, bem como a assistente social participou do grupo temático de habitação social no mesmo conselho durante os trabalhos de formulação do III ${ }^{\circ}$ Plano Diretor de Pelotas. O representante da FRAGET no conselho justificou a necessidade de captação de recursos PAC para Vila Farroupilha. Esse loteamento próximo à rodoviária da cidade apresentava péssimas condições de moradia e sem qualquer infraestrutura de

\footnotetext{
${ }^{14}$ Nessa entrevista se abordou o repertório das moradoras que atuam na Associação de Catadores de Lixo.
} 
serviços urbanos de água, esgoto, eletricidade etc. A participação no espaço institucional de discussão do plano diretor possibilitou formular demandas também referentes à elaboração de cadastro dos vazios urbanos para fins de criação de uma política realista destinada a remediar o déficit habitacional da cidade de Pelotas. Por fim, a associação FRAGET está engajada na luta pelo emprego sob o modelo de economia solidária dos catadores de lixo, estes tão depreciados pelas políticas locais vigentes no período de investigação (2009-2013).

\section{Considerações Finais}

Os moradores e lideranças dos loteamentos Navegantes I e II, Anglo e FRAGET concebem o associativismo como significativo para resolução de necessidades e problemas de moradia e infraestrutura, porém chama atenção o movimento flutuante ou circular da ação, que oscila do particular (privado) para o geral (público) e vice-versa. O associativismo dos moradores consiste em organizar as necessidades básicas, demandas imediatas, atividades lúdicas (festas), reuniões, cursos de capacitação, encontro das mulheres, em determinados momentos, são iniciativas articuladas à ação dos atores - partidos, poder público, ONGs. Todavia, a participação no espaço de debates do plano diretor da cidade de Pelotas foi ínfima, com exceção da FRAGET. Pode-se considerar que a fraqueza da participação democrática volatiza a autonomia pública dos moradores, indispensável para assegurar a autonomia privada constituída intersubjetivamente. De modo que os pontos de vista dos moradores e das lideranças das associações, no que tange aos problemas da periferia, ou seja, dos espaços de "baixa renda diferencial", reproduz as condições desiguais de oportunidades de acesso aos e controle dos recursos públicos destinados à infraestrutura e à habitação.

As necessidades imediatas levam à resistência dos moradores ao que os oprime e os ignora. O cotidiano se apresenta como espaço vulnerável à reprodução das relações do poder dominante, porém espaço de resistência à unicidade e uniformidade da concepção de habitat dos promotores imobiliários. Simultânea e sucessivamente, a linguagem cotidiana traduz a periferia como o espaço da pluralidade de significados, de representações e de disposição do agir que reage à unicidade e consistência dos projetos e programas de intervenção no espaço urbano. De maneira que a periferia se fundamenta como o lugar de moradores despossuídos, cujas práticas estão 
ancoradas no terreno das necessidades econômicas e sociais. Na periferia, o cotidiano enquanto necessidade prática é a revisão da ação precedida e silenciada ("vivido"), é a reação ao esquecimento do sentido da história social e do indivíduo. Por isso, o espaço diferencial ressignifica a condição de pobreza, de discriminação, de oposição entre ricos e pobres e de segregação social.

A estratégia de resistência, de solução de problemas é o confronto direto e imediato, e a busca de mediadores, porta-vozes políticos que se inclinam à "questão social", secretarias municipais e as organizações não governamentais. $\mathrm{Na}$ maioria das vezes, os moradores dos loteamentos Navegantes I e II e Loteamento Anglo não obtêm o retorno por parte da prefeitura, ainda assim o trabalho das ONGs, a exemplo da ONG C.A.P.A. (Centro de Apoio ao Pequeno Agricultor), a mais citada pelas lideranças e moradores, atende à comunidade ao oferecer cursos de qualificação, distribuição de alimentos e palestras.

Os programas sociais e institucionais de políticas de assistência e urbanas, como Fome Zero, Bolsa Família, PMCMV, PAC etc., embora parcialmente preencham as necessidades de renda familiar e moradia (e infraestrutura), apresentam um repertório dominante do cotidiano planejado e homogêneo. Com os objetivos de inclusão das camadas da população de baixa renda, os programas sociais intervêm no espaço urbano com a estratégia de dominação, paradoxalmente emanam do mesmo espaço, os repertórios dos moradores, cujas variações intraindividuais em cada um dos loteamentos pesquisados - Navegantes I e II, Anglo e FRAGET - expressam pontos de vista, os quais reagem e criticamente atravessam a oferta de bens dominante.

\section{Referências}

BONDUKI, Raquel; BONDUKI, Nabil.

(1979). Periferia da Grande São Paulo: reprodução do espaço com expediente de reprodução da força de trabalho. In: Ermínia Maricato (Org.); A produção capitalista da casa (e da cidade) no Brasil industrial. São Paulo: Editora Alfa-Omega, p. 117-154.

BOURDIEU, Pierre. (1979). 0 poder simbólico. Lisboa: Difel.
BOURDIEU, Pierre.

(1996). Espaço Social e Espaço Simbólico. In: Razões práticas: sobre a teoria da ação. p.13 $-33$.

LAHIRE, Bernard.

(2002). Homem plural: os determinantes da ação. Petrópolis, RJ: Vozes.

LAHIRE, Bernard. (2006). A cultura dos indivíduos. Porto Alegre: Artmed. 
LEFEBVRE, Henri.

(1977). Estrutura social: a reprodução das relações sócias. In: Marialice Mencarini FORACCHI; José de Souza MARTINS (Orgs.); Sociologia e sociedade: leituras de introdução à sociologia. Rio de Janeiro: Livros Técnicos e Científicos. p. 219 - 252.

LEFEBVRE, Henri.

(2008). A revolução Urbana. Belo Horizonte: UFMG.

MARTINS, José de Souza.

(1992). Subúrbio: vida cotidiana e história no subúrbio da Cidade de São Paulo. São Paulo: Editora Hucitec.

MAUSS, Marcel.

(2003) Ensaio sobre a dádiva: forma e razão da troca nas sociedades arcaicas. In:

Sociologia e antropologia. São Paulo: Cosac Naify. p.185-314.

SINGER, Paul.

(1979). “Ouso do solo urbano na economia capitalista". In: Ermínia Maricato (Org.); A produção capitalista da casa (e da cidade) no Brasil industrial. São Paulo: Editora AlfaOmega. p. 21-36.

BRASIL. Governo Federal.

(2011). Ministério de Desenvolvimento Social. Programa. Bolsa Família (PBF). Programa Fome Zero (PFZ). Disponível em: www.mds. gov.br. Acesso em: 11 de dezembro de 2011.

BRASIL. Instituto Brasileiro de Geografia e Estatística (IBGE).

(2011). Sinopse do Censo Demográfica de 2010. População rural e urbana de Pelotas. 01 de julho de 2011.

\section{C.U.FA. CENTRAL UNICA DAS FAVELAS BASE} PELOTAS.

(2013). "Atraso na entrega de casas no Anglo". Disponivel em: http://cufapelotasrs.blogspot.com.br/2013/07/atraso-naentrega-do-loteamento-anglo.html. Acesso em 09 de agosto de 2013.

INSTITUTO PESQUISAS DE OPINIÃO (IPO). (2002). Relatório de Pesquisa: avaliação do déficit habitacional de Pelotas, Rio Grande do Sul. Pelotas, mimeo.

PELOTAS. PREFEITURA MUNICIPAL. Secretaria Municipal de Gestão da Cidade e mobilidade Urbana. Relatório aponta déficit habitacional de Pelotas em 11,93. Pelotas, 15 de junho de 2013. Disponivel em: http://www.pelotas. rs.gov.br/noticias/detalhe.php? controle= MjAxMyOwNi0xNQ==\&codnoticia=34439

Acesso em 09 de agosto de 2013.

RIO GRANDE DO SUL. Governo Estadual. Secretaria da Saúde. Programa uma Infância Melhor (PIM). Disponivel em: http://www. pim.saude.rs.gov.br/a_PIM/php/paginaQuemSomos.php. Acesso em 09 de agosto de 2013.

\section{Recebido em}

janeiro de 2014

\section{Aprovado em}

abril de 2014 